\title{
User-centered gamification: how to design, develop and evaluate it
}

\author{
Ana Carolina Tomé Klock \\ Federal University of Rio \\ Grande do Sul \\ Porto Alegre, Brazil \\ actklock@inf.ufrgs.br
}

\author{
Isabela Gasparini \\ Santa Catarina State \\ University \\ Joinville, Brazil \\ isabela.gasparini@udesc.br
}

\author{
Marcelo Soares Pimenta \\ Federal University of Rio \\ Grande do Sul \\ Porto Alegre, Brazil \\ mpimenta@inf.ufrgs.br
}

\section{PRESENTATION}

Gamification is the use of game elements in contexts which the main purpose is not playful and it has been widely applied in order to motivate and engage users [5][11]. However, since each user has different characteristics, the user experience during the interaction with these game elements becomes singular and it does not always have the expected outcome. Many studies point out the influence of users profile on the effectiveness of gamification in relation to the purpose of its application [1][2][4][3][6][7][9], but surprisingly little has been explored about the processes of design, development and evaluation of the user-centered gamification to promote a better user experience and, consequently, a greater motivation and engagement [8]. Thus, this course aims to cover personal, functional, psychological, temporal, playful, implementable and evaluative properties of gamification in order to enable the participants to design, develop and evaluate a user-centered gamification, while allowing the improvement of the gamification results. For this, the methodology to be employed by this course involves two parts: theoretical and practical. In the theoretical part, the exposition of concepts related to gamification will be carried out, followed by examples, in an interactive way with the participants. In the second part, participants will be invited to bring examples of scenarios that they would like to work on and the concepts presented will be put into practice so that the public can participate and share their experiences while designing the usercentered gamification.

\section{EXTENDED SUMMARY}

To achieve the expected results, the course will cover the following topics:

- Gamification fundamentals: include the concept, origin, MDC (Mechanics-Dynamics-Components) framework and common game elements applied;

- Gamification personal aspects: explain the users' characteristics that can influence the gamification results, such as

Permission to make digital or hard copies of all or part of this work for personal or classroom use is granted without fee provided that copies are not made or distributed for profit or commercial advantage and that copies bear this notice and the full citation on the first page. Copyrights for components of this work owned by others than the author(s) must be honored. Abstracting with credit is permitted. To copy otherwise, or republish, to post on servers or to redistribute to lists, requires prior specific permission and/or a fee. Copyright 2018 SBC.

IHC 2018, Anais Estendidos do XVII Simpósio Brasileiro sobre Fatores Humanos em Sistemas Computacionais.

Outubro 22-26, 2018, Belém, Brasil

Minicursos sex, age, game preferences (i.e., player type), personality traits, and culture;

- Gamification functional aspects: comprise the application domain and the tasks to be performed by the users, which will be exemplified in educational context;

- Gamification psychological aspects: describe the emotional influence of gamification, comprising some stimuli as motivation, engagement and fun;

- Gamification temporal aspects: consist of the interaction evolution with the gamified application (i.e., player journey) and the use of regular reinforcements to motivate users and keep them motivated (i.e., schedules of reinforcement);

- Gamification playful aspects: relate the MDC framework with the previous gamification aspects, explaining how to design the user-centered gamification step by step;

- Gamification implementable aspects: illustrate the development process with the Lifecycle Model for Interaction Design [10], but any Software Engineering (e.g., Waterfall) or Human-Computer interaction (e.g., Star) model can be adopted, according to the skills and knowledge of the development team;

- Gamification evaluative aspects: present the evaluation based on a protocol, defining the hypothesis and metrics, collecting data with the users' consent, and using statistical methods (with R) to refute or accept null hypothesis.

\section{TARGET AUDIENCE}

This course will attract, among others, the following public:

- Academics and Professionals who are interested in learning about gamification fundamentals and how to apply it;

- System Analysts, Designers or User eXperience Specialists looking for a way to make their applications more attractive or to promote the loyalty of users.

No prerequisites are required to attend this course.

\section{AUTHORS' BIOGRAPHY}

Ana Carolina Tomé Klock is a PhD Candidate in Computing at Federal University of Rio Grande do Sul (UFRGS), while having a Master's degree in Applied Computing from Santa Catarina State University (UDESC). Her main interests 
are Gamification, Human-computer Interaction, Adaptability, Games, and Education.

Isabela Gasparini is a Professor at Santa Catarina State University (UDESC). She received her PhD and Master's degree in Computer Science from Federal University of Rio Grande do Sul (UFRGS). Her main interests are HumanComputer Interaction and Education, focusing on Adaptability and Personalization, Usability Evaluation, User Modeling, Technology Enhanced Learning, Gamification, Data Analytics, Context-aware Systems, and Cultural aspects.

Marcelo Soares Pimenta is a Full Professor at Institute of Informatics (INF), Federal University of Rio Grande do Sul (UFRGS), in Brazil. He is head of LCM, the INF-UFRGS Computer Music Laboratory. He received his $\mathrm{PhD}$ in Informatique at Universit Toulouse 1, France, in 1997 and the bachelor and master's degree in Computer Science at UFRGS in 1988 and 1991, respectively. Since 1998, he is member of a multidisciplinary research group at UFRGS working with topics in Human-Computer Interaction, Software Engineering, and Computer Music with emphasis in the integration of these areas.

\section{COURSE DURATION}

Three hours.

\section{COURSE LANGUAGE}

English (Portuguese is an option if it is the preference of all attending participates).

\section{INFRASTRUCTURE AND MATERIALS NEEDED}

Projector, Notebook with USB input, and stationery materials (e.g., blank or recycled sheets of paper, colorful pens - purple, blue, green, red, pink, orange, yellow and black ones, and post-its).

\section{REFERENCES}

1. Attali, Y., and Arieli-Attali, M. Gamification in assessment. Computers \& Education 83 (abr. 2015), 57-63.

2. Bittner, J. V., and Shipper, J. Motivational effects and age differences of gamification in product advertising. Journal of Consumer Marketing 31, 5 (2014), 391-400.

3. Codish, D., and Ravid, G. Adaptive approach for gamification optimization. In Proceedings of the 2014 IEEE/ACM 7th International Conference on Utility and Cloud Computing, IEEE Computer Society (Washington, 2014), 609-610.

4. Conaway, R., and Garay, M. C. Gamification and service marketing. SpringerPlus 3, 1 (dez. 2014), 1-11.

5. Deterding, S., Khaled, R., Nacke, L. E., and Dixon, D. Gamification. In CHI 2011 Gamification Workshop Proceedings, ACM Press (Vancouver, 2011), 12-15.

6. Gil, B., Cantador, I., and Marczewski, A. Validating gamification mechanics and player types in an e-learning environment. In Proceedings of the 10th European Conference on Technology Enhanced
Learning, G. Conole, T. Klobučar, C. Rensing, J. Konert, and É. Lavoué, Eds., Springer International Publishing (Cham, 2015), 568-572.

7. Herbert, B., Charles, D., Moore, A., and Charles, T. An investigation of gamification typologies for enhancing learner motivation. In Proceedings of the 2014 International Conference on Interactive Technologies and Games, IEEE Computer Society (Washington, 2014), 71-78.

8. Klock, A. C. T., Gasparini, I., Kemczinski, A., da S. Hounsell, M., and Isotani, S. One man's trash is another man's treasure. In Anais do Simpósio Brasileiro de Informática na Educação, SBC (Porto Alegre, 2015), 539-548.

9. Pedro, L. Z., Lopes, A. M. Z., Prates, B. G., Vassileva, J., and Isotani, S. Does gamification work for boys and girls? In Proceedings of the 30th Annual ACM Symposium on Applied Computing, ACM Press (New York, 2015), 214-219.

10. Rogers, Y., Sharp, H., and Preece, J. Interaction Design, 3 ed. John Wiley \& Sons, Hoboken, 2011.

11. Werbach, K., and Hunter, D. For the Win. Wharton Digital Press, Philadelphia, 2012. 